\title{
Sociocultural Bases of State - Legal Development Coding
}

\author{
Aleksey Ovchinnikov \\ Aleksey Mamychev \\ Diana Mamycheva \\ Vladivostok State University of Economics and Service \\ Email: kafedra_tgp@mail.ru
}

\section{Doi:10.5901/mjss.2015.v6n3s4p67}

\begin{abstract}
The article exposes to a holistic consideration the socio-cultural foundations of the state - legal development, discusses traditions and innovations in the study of the latter, and is formulated and argued the author's theoretical and methodological reconstruction program of data bases. The authors prove that the sociocultural foundations legitimize specific historical functioning of public government institutions and their further transformation through the creation of special socio-political state of society - political metanarrative. It is shown that socio-cultural bases are always paired with a dominant socio-political and legal intellectual work of the society, its possibilities and limits, are a set of trends and vectors of public government transformation. In the context of the article a model of analysis of socio-cultural implications of state-legal development that has several levels are provided: a) archetypal (moral-cognitive intuition, archetypal codes, images, symbols, basic scripts and forms of political activity); b) "quasiisometries" of archetypal structures; c) empirical - everyday (usual) socio-political interaction and its emotional and psychological component; $d$ ) institutional (political institutions, institutional and regulatory activity and other public legal practice); e) doctrinal and ideological-conceptual; f) "quasiisometries" of institutionally-organized public-legal society, consisting of positive (socioculturaly approved) and negative (harmful, dangerous) political and legal phenomena and processes; $g$ ) the level of socio-political integrity.
\end{abstract}

Keywords: legal archetype, state-legal development, political process, socio-cultural conditionality, legal doctrines.

\section{Introduction}

In modern research, to analyze the socio-cultural foundations of coding state - legal development, apply a package systemic approach This approach is the possibility of adequate study of depth cultural attitudes, their influence on the development of forms of power-legal organization, motives and subjects (typed) of legal and social interaction, reproduction style of legal thinking, cognitive attitudes that determine the perception and assessment of legal institutions and legal activities (Mouffe Ch., 2000).

It is no coincidence that in the context of legal anthropology the research work is aimed at the reconstruction, first of all, everyday social and legal interaction in the system of personality - society - state, the specifics of which reveals regularities and features of the legal existence of the society. It is known that at the level of legal and institutional organization of many geopolitical and geolegal spaces are similar, typologically homogeneous. However, at analyzing of a legal existence, everyday interaction and mass style understanding of legal phenomena and processes they, respectively, are significantly different (Rouland, 1988).

Actually, strictly speaking, there is no state - legal space matching on the specifics of everyday legal residences. Even taking into account the similarity of the vector of political and legal development of most European countries, there are significant differences in everyday legal life and in the specific of mass and the political and legal reality perception. On the contrary, it should be assumed that the heterogeneity in the legal life is characteristic of not only of the individual (sovereign, civilizational) legal-political spaces, but also manifests itself (heterogeneity) in the context of a single social system. So, for example, E. A. Lukashev indicates that "the heterogeneity of socio-normative regulators in any European society, the existence of subcultural groups with different orientations, the desire of migrants from different civilizations, to impose their values result in a conflict of cultures" (Lukashev, 2006, p. 254).

Moreover, the actual legal and political practice has shown that the draft of legal standardization of the development of social systems leads to chaos and "sedition" in the functioning of not only internal protoculture space, but also external international legal cooperation. The illusory nature of this project is obvious, as standardization and 
unification of the legal development of heterogeneous cultural spaces is impossible.

In this respect, the reconstruction of social and cultural foundations of the state and legal development of a society, the understanding of the process of succession, dominants and factors affecting the stability and orderliness of social interaction, archetypal levels of conditionality legal culture of a society is of not so much theoretical, but practical interest. Such researches are relevant and useful because they involve formation of an adequate legal policy, areas of institutional reform, the formulation of clear principles and priorities of legislative activity, as well as contribute to, in the strategic plan, ensuring the national security of Russia.

Indeed, for an adequate understanding of the national legal reality, the mechanisms of its development and functioning, continuity and transformation of logic and style of legal reasoning, evaluation of existing political and legal institutions and structures it is necessary, first of all:

- first, to recognize the inferiority and narrowness of rational methods of research in law, because the legal life is much more varied and difficult, and the perception and knowledge of legal and related phenomena is not limited by rationalized techniques;

- secondly, the reorientation of legal issues with the study of logical and methodological problems, often divorced from the immediate process of cultural evolution of law and state, legal life of the nation, the real (current, typed in society) practices of everyday social and legal interaction, the study of life, the philosophical foundations of legal life;

- third, to recognize the crisis of Western rational type of legal consciousness, "inculcation" which in other moral spaces causes legal nihilism and political anomie, and guide the intellectual efforts to find out of the crisis through the return on the position of axiological rationality and protoculture conditionality;

- fourthly, the creation and justification of new models of legal society, an adequate moral-ideological and sociocultural environment, the development of legal and political thought and practice on the basis of their own civilization dominat and development opportunities;

- fifthly, the denial of objective truth and beliefs to produce hypotheses of scientific knowledge, since in this interpretation other forms of perception and cognition of reality, as well as other kinds of knowledge - religious, everyday, etc. lose the status of "objectivity".

For example, P. Berger and T. Luckmann in his most famous work, has repeatedly stressed that the logic is not peculiar to institutions as such, and not their external functionality, but the "way of reflecting on them". In other words, the reflexive consciousness transfers the property of logic (or, in this context style worldview, perception and evaluation of the existing reality - ed.) at the institutional order" (Berger \& Luckmann, 1966, p. 108). In the same context, well known sociologist R. Merton notes, that the logic of functioning and functional competence of institutions and structures is mediated by the social environment. In its turn, the institutions not meeting the logic of the development of the sociocultural environment (imported or abstractly constructed or lost its social significance, etc.) cause dysfunction in the institutional development of society, lead it to a crisis, an unstable fuctioning. Therefore, "functional deficiencies of the formal structures generate alternative (unofficial) for more effectively satisfaction of the existing needs" (Merton, 1957, p. 198).

\section{Literature Review}

In modern literature it is possible to allocate a sufficient number of projects aimed at the reconstruction of the cultural foundations of certain phenomena of political-legal, socio-economic and spiritual life of the society (Mordovtsev, 2002). As a rule, in the field of scientific reflection is actualized the search of sociogenic matrix corresponding to a particular society, group, social stratum, which characterizes the differences in attitudes, behavioral orientations, interests and needs, value world and worldview (Mostovaya, 1995, p. 72).

In General, the tradition of the study of the foundations of the state and legal development can be grouped into four main areas.

First, that is the group of researchers who analyze the political and legal development in structural and functional terms, these include works by such authors as G. Almond, K. Deutsch, E. Durkheim, D. Easton, G. Kelsen, K. Marx, R. Merton, T. Parsons, P. Sorokin and others (Merton, 1957).

Secondly, this concept version, focusing the aqttention on the institutional and regulatory encoding state-legal development issued from pen of such authors as H. Arendt, M. I. Baytin, I. N. Homer, A. F. Maliy, D. Nort, J. Wallace, V. E. Chirkin, etc. (Political culture..., 2007)

Thirdly, it is a political, sociological and state doctrine, focusing on the understanding of the state and legal development as complicated and dynamic system of public government relations (Duby, 1991 \& Rouland, 1988). This 
approach to the interpretation is presented in the works of N. N. Alekseev, P. Blau, Y. V. Vereshchagin, N. Luhmann, G. V. Maltseva, L. S. Mamut, V. Podorog, O. Kharkhordin, E. Jünger, etc.

Finally, in the fourth tradition the political and legal development can either be specified by a certain type (Ovchinnikov, Mamichev, Manastirniy. \& Tyurin, 2009) of political rationality (J. Agamben, M. Weber, P. Bourdieu, K. Crouch, M. Foucault, etc.), or as a socio-psychological attitudes (B. de Jouvenel, I. A. llin, M. N. Korkunov, L. I. Petrazycki, I. L. Solonevich, etc.), or mass political image of the state and legal reality (real or virtual), by dominant views, simulares, archetypal predispositions of society, etc. (J. Baudrillard, D. V. Ivanov, I. A. Isaev, Y. Evola, M. Eliade, J. Ellul, etc.), organizing socio-political intellectual work of the actors and processes of institutionalization of the state space (Mostovaya \& Skorik, 1995).

In addition, a number of modern studies have recently been devoted to state and legal evolution, the development of various forms of political and legal organizations, a number of governmental institutions and practices within a particular socio-cultural environment (Muouffe, 2000). However, these fundamental developments, theoretical and methodological innovations, formulated trends of development of public government relations rarely are subjected to analysis of existing state and legal systems and the prospects for their transformation based on socio-cultural coding of their evolution (Berger \& Luckmann 1966). All of this requires a comprehensive study of the bases of the state and legal development based on socio-cultural factors and its transformation (Lukasheva, 2006.). In this article the theoretical, methodological and structural components of such a research program are formed.

\section{Methods and Materials}

At the moment there are no heuristically adjusted research methods of socio-cultural encoding of state and legal development. Although, for the compilation of General methodological context, it is nessesary to consider the following theoretical and methodological orientations:

1. Religious worldview and its role in the life of a particular people;

2. Relations "Aliens" and "Own";

3. Relations "Own" and "Alien".

4. The value of the family (clan) and it interests.

5. Traditional attitudes towards government and other authorities ("distance of power ");

6. Relation to work and to the property.

7. Relationship to applicable law (the"Law"-"Custom"-"Traditions").

We believe that these points will let to come most closer to understanding of the socio-cultural foundations of the state and legal evolution of a particular society, the main vectors of development.

As a methodological principles can be distinguished the followings:

1) the principle of supplemented in the understanding of the behavior of individuals and groups in the legal and political spheres, when, on the one hand, the legal and political institutions, structures and mechanisms largely determine human activity, its nature and direction, and on the other, the efficiency and stability of the legal and political components of the national statehood is determined by "human factor";

2) the principle of "understanding interpretation", i.e. the concept is structured by methods of understanding and explanation, which generally corresponds to the heuristic settings of postnonclassical (understanding) science. This approach allowed us to consider the scope of legal and political everyday life, peculiarities of their political and legal activity, to identify the factors of sustainable development of the state and institutions of civil society, to assess the criteria for determining the effectiveness of the law in its socio-cultural dimension;

3) ethno-cultural conventionality, means that existing in the society of value-normative systems have specific historical and socio-communicative nature. Thus the knowledge of the latter is due to socio-cultural and historical context, any legal phenomenon or process theoretically and philosophically is loaded and conditioned by socio-cultural factors and dominantes;

4) integrity - is a methodological principle of systemic and organic unity, interaction and interconditionality of all elements of the socio-legal society;

5) objectivity - as a methodological principle of the present study involves the orientation of the reconstruction of existing concepts and characteristics, legal ideology, independent of the will and consciousness of;

6) instrumental-legal realism, means the knowledge of social and cultural factors and dominants necessary not only for understanding law and legal world views, but also for the management of real socio-legal and political processes. 


\section{Results and Discussions}

Central to contemporary research of socio-cultural implications of state power and power relations is the reconstruction of social and cultural codes (archetypes, dominants) contributing to the development of the political system and culture of the society, as well as levels of conditionality. However, the levels, the content and forms of socio-cultural implications of the political process are one of the controversial problems (Kirsanova \& Korotina, 2014).

The complexity and ambiguity of such research is, on the one hand, in excess of the "psychologization" of this research project that does not always meet the objectives of the analysis; and on the other, in some "restraint", "caution" with whom the researcher refers to deep socio-cultural structures and political right culture, due to the lack in the theory of sufficiently clear and authoritative position on the national study of the bases of power, politics, law, and other legal and political phenomena (Political culture, 2007).

However, it is clear that the formation of political and socio-legal aspects of behavior, patterns, images and conventions of perception of political and legal phenomena and processes of contemporary reality are largely determined by the memories "about the events, beliefs, feelings stored for centuries. All of this is the common heritage of the majority. Even if it is not realized, even if to abandon it, it remains the basis, the Foundation of the nation -- and some invisible influence on our opinions and actions" (Moscovici, 1998, p. 173).

This methodological turn in the study of political and legal cultures of the society and state legal process is based on the system analysis of all factors and patterns of development of specific socio-cultural environment. Thus central to these studies is the analysis of behavioral patterns (cultural models) and clichés and stereotypes of thinking, characteristic for members of a particular culture. In this context, fair is position of the Sapir, announced at the Congress of the British Association of anthropologists, according to which culture on the socio-psychological level imposes certain styles of political thinking and behavior, including the typical political rituals and symbols, even the postures and gestures (MFA, Moscow, 1988, p. 49-50).

Therefore, without understanding of the socio-cultural implications it is impossible to adequately analyze patterns and randomness in the development of institutional power-the legal system of a society, the national political process, the system of practices of public - legal interaction in the system of personality - society - state, to carry out political modeling of modern development of society, as well as to adequately identify the roles and tasks of legal policy of the state.

It seems to us, based on the foregoing theoretical and methodological principles, it is appropriate to emphasize the structure of the archetypal conditionality of the state and state-legal development. As already noted above, the recurrent political and legal experience forms certain unconscious (sustainable, collective) factors and dominant interactions that become archetypal structures or socio-cultural codes (archetypes) for the development of the political life of. At the same time, these archetypal patterns affect our perceptions and experiences, trying to organize them in accordance with the existing. Socio-political archetypal patterns and models, according to our definition, represent a crystallization of state legal experience of the nation, fixing the baseline script of legal - political thinking, regime interaction between the individual, society and the state, shaping trends in institutional - power and socio-legal organization of society.

1. The archetypal level of society is a primary, basic level of formation of political and legal culture of the society, in fact, representing the. It is a carrier of social and cultural reinforcement, which determines specificity of the institutionalization of certain phenomena and processes legal activity and forms a "congruent semantic and pragmatist perspective" (M. Mead, D. Clachon, etc.). Some researchers propose to call such a primary level, a particular layer of culture, which is formed mainly at the level of mass unconsciousness manifesting itself when moving from private life to the socio-cultural psycho local human community and back. At the same time, the particular culture exists as a phenomenon of individual unconsciousness, reflecting the General trends of private life and in many ways causing the formation of personality and its social roles, and the nature of interaction with other individuals" (Mostovaya \& Skoryk, 1995, p. 70). Meaningfuly characterizing this level, we can distinguish the following components: moral and cognitive intuitions; overrational values (archetypal codes); archetypal images and ideas; archetypal prelegal primary noms (Ovchinnikov, Mamychev, Manastirniy \& Tyurin, 2009).

2. Quasiisometries of archetypal structures is a socio-cultural space, where are rooted and are acting main sociopolitical and legal archetypes of the local community (ethnos, ethnic minorities, ethnic groups, etc.)

Namely, at this micro level is taking part continuous, slow formation of social and cultural dominants, reproducing the specificity and uniqueness of the state legal culture of a particular society and its special power-law interaction.

Therefore, this dimension reflects the so-called "derivatives" "societaria" factors and sources. In other words, 
derivativeness means that the socio-political codes and factors contributing to national political reality, are expressed in the customs, traditions, style perception for political and legal phenomena and processes, moral and spiritual landmarks and the patterns of interaction in the system of personality - society - state, in other national and religious artifacts, which determines the features of political culture, forms and practical schemes of satisfaction the spiritual and material needs, their accompanying rituals.

The ratio between the archetype and its derivatives is not informative, and energy-motivational. For example, K. Jung himself has stressed that the archetypal basis of society does not apply to inherited notions, but to internal dispositions that produce the same representation. The first level determines the content and form of streamlining legal-cultural life of society. True is writen in this context of I. V. Mostovaya and A. P. Skorik that this level initiates the formation of the primary domestic relations, rituals, primary social norms, values and evaluations. In short, it forms "partly anreflexive everyday world of social interactions - with its established traditions, special (for internal use only) social symbolism, special language, which almost is intuitively understood by "owns"'" (Mostovaya \& Skorik, 1995).

3. The empirical level of the state-legal society is a common legal and political interaction in the context of which is carried out daily (practical) behavior of subjects on the basis of established and successively reproducing forms and typed models of socio-authority interaction, achievement of subjective interests and needs Essential on this level is, of course, not only the behavioral tradition", but also "oral tradition", and also formed on the previous levels moral-cognitive readiness and installation in the existing perception of reality, legal emotions and attitudes (emotional-psychological component of everyday political interaction). Namely practical (usually daily) behavior reflects real, unlike, for example, from authorized (officially recognized) customs, the specificity of the socio-political life of the nation, ethnic groups, specific.

In its turn, the emotional and psychological side reflects the inner component of everyday socio-political interaction, which is based on the emotional and psychological experience of individuals.

4. Doctrinal (theoretical) level of state-legal society is deepest, essential (conceptual, ethical, symbolic) features of political and legal phenomena, processes and is linked to their performance and rating in political thinking. This level is integrative, unifying the existing cultural content with basic, hypotrichosis installations, the dominant socio-political development, etc. It includes the following elements that characterize this level from the perspective of archetypal conditionality: axiological (normative values), conceptual (political and legal theory, doctrine, categories and concepts) and symbolic (the existing state legal symbols and rituals) components.

5. The institutional level of the state-legal society respectively embodies historical patterns of specific socioenvironment, institutionalizes established, typed forms and models of positive interaction in the system of personality - society - state. P. Berger and T. Luckmann rightly belived that, "the institutionalization takes place wherever is a reciprocal typification of customary action figures of various kinds. "In other words, any such typification is the Institute", in its turn, "the logic of institutional development - ed.) tend not to institutions and their external functionality, but the method of reflection. In other words, the reflexive consciousness transfers the property of the logic to the institutional order." Therefore, the researchers conclude, "institutions always have a history, a product of which they are, it is impossible to adequately understand the Institute, without understanding the historical process in which it was created" (Berger \& Luckmann, 1966, p. 97).

Right is Professor A. Y. Mordovtsev indicating the effect of the regularities in the development of legal and institutional organization: "on the one hand, existing state and legal institutions (in particular, elements of the legal system) inevitably determine, regulate, direct and even evaluate the behavior of an individual as lawful or unlawful, and on the other, the efficient functioning of these institutions, the direction of their development, specific activities, role and importance in society and the state always depend on a subjective or "personal" factor, i.e. there is a mutual addition, a balance of subjective and objective in the legal sector regulation of social relations" (Mordovtsev, 2002, p. 53-54).

So this level, in addition to existing state - legal institutions and structures, reflecting the essentially static element of institutional level, also includes dynamic elements such as institutional and regulatory activity (legislative, law enforcement, judicial and other legal and political practice), as well as the institutional and regulatory activity of the citizens and various public institutions and structures (Kononova, Yakimova, 2013).

6. Quasiisometries of state-legal society is a level, reflecting the positive (with sociopolitical approval) and negative (harmful, dangerous) political and legal phenomena and processes. At this level the interaction of the existing institutional, government and legal organizations with real behavioral practices, refraction of existing institutions in the national political thinking take place. 
In addition, it should be assumed that the political - legal space is a particular area of social life, in which the interaction of social actors about the organization and the exercise of political power, the implementation of specific interests and needs, the direct management of public affairs and the organization of political and legal order of interaction of individuals, their social communities, organizations, institutions, etc. is carried out (Andreev \& Bordyugov, 2004, p. 7). Thus, political-legal space includes institutional structure, its political, legal, cultural and moral framework that provides a specific state - legal regime. In the public consciousness forms certain conceptions of the individuals social space, thereby predetermining political - legal organization of the last, and the political interaction of actors within this space defines the true meaning and importance of political and legal institutions, institutions in the existing conditions of place and space.

7. The level of socio-political integrity characterizes the culture of a particular society as a holistic phenomenon, reflects its specificity and adaptive capacity to face the challenges of modernity. It expresses three main elements that characterize the specificity of a political and legal cultures, institutional development perspectives, the possibilities of adaptation to external borrowings of certain institutions, to import any ideas and doctrines, and also sustainable forms and ways of perception and evaluation of the phenomena of political and legal reality, socio-cultural standards and models of interaction in the system of personality - society state. These elements should include follwings:

a) the dominating type of socio-political and legal thinking, reflecting, respectively, the condition (linguistic, communicative, historical) that reveals and updates the state legal existence for the subject as a special "background", the context of the existence of real political - legal phenomena;

b) socially significant and legitimate standards and models of socio-political and legal interaction, reflecting the current level of institutional organization and in everyday political activities sustainable models of interaction in the system of personality - society - state, as well as established and adopted by a majority system of perception and assessments (national cognitive matrix), occurring inside the society and outside political - legal phenomena and processes. This component reflects the highest form of human activity that have a collective origin (E. Durkheim), as well as acting in the society dominant political and legal ideology;

c) socio-legal and political psychology of the nation, reflecting in integrative form of socio-political sensitivity and socio-political stereotypes of imperious interaction. Moreover, this political sensitivity, cognitive set and readyness (which define the style, story line and moral predispositions) are reflected in the prevailing patterns of behavior, moral norms, mass estimates and judgments concerning various political and legal phenomena and processes. For example, a representative of the school of annals J. Duby said that "systems of images, ideas, that are in different groups or countries are social formation, are combined in different ways, but always underlie human ideas about the world and about their place in the world and, therefore, determine the actions and behavior of people" (Duby, 1991).

\section{Concluding Remarks}

In the context of the analysis of state-legal development it should be spoken of a single political - legal order, which is based on political, legal norms, ideas, values and ideals of the institutional organization of society, ensuring the orderliness of social relations and reflecting the peculiarities and regularities of development of socio-cultural system.

Important for understanding of the state-legal development trends is the analysis of socio-cultural implications of public government and socio-legal relations, as well as the reconstruction of the socio-cultural codes (archetypes, dominants). Socio-cultural conditionality of state-legal development of the modern political process is associated with the crystallization of the political and legal experience of the nation, fixing the baseline legal and political thinking activity, modiness of interaction between the individual, society and the state, shaping trends in the institutional power of social organization.

To describe the socio-cultural integrity of the state - legal development, a separate political and legal phenomena and processes in the work was developed the following multilevel model:

1) archetypal level (moral-cognitive intuition, overrational values, archetypal images and symbols, socio-cultural personally public interaction;

2) quasiisometries of archetypal structures (socio-legal and political codes and dominants, which are expressed in political and juridical customs, traditions, style perception for political and legal phenomena, moral and spiritual landmarks and the patterns of interaction in the system of personality - society - state);

3) empirical level of the state-legal society ("behavioral tradition" and "oral tradition", socio-political and legal 
emotions, settings);

4) doctrinal level - axiological (normative-value), conceptual (political and legal theory, doctrine, categories and concepts) and symbolic (the existing state - legal symbols and rituals) components;

5) institutional level - the existing political institutions and structures (static measurement), the institutional and regulatory activity of the state (legislative, law enforcement, judicial and other public-government activity), institutional and regulatory activity of the citizens and various public institutions and structures (dynamic elements);

6) quasiisometries of state-legal life of society - positive (with sociopolitical approval) and negative (harmful, dangerous) political and legal phenomena and processes;

7) the level of socio-political integrity is the dominant type of socio-political thinking activity, socially significant, legitimate standards and models of socio-political interaction, as well as established and adopted by a majority system of perception and assessments (national cognitive matrix), socio-political psychology of the nation.

\section{References}

Andreev, D.F. \& Bordyugov G.A. (2004). The Space of power from St. Vladimir to Vladimir Putin. M.; SPb. p. 160.

Duby, J. (1991). The Development of historical studies in France. M. pp. 255.

Lukasheva, E.A. (2006). Human rights: a clash of cultures // Our difficult path of the law: proceedings of a legal philosophical readings to the memory of academician V. S Nersesyanc. M. pp. 241-255.

Mead, M. (1988). Culture and the world of childhood. M. pp. 270.

Mordovtsev, A.Y. (2002). National legal mentality: introduction to the problem. Rostov on Don. p. 230.

Moscovici, S. (1998). The Age of the crowds. Historical treatise on mass psychology. M. pp. 480.

Mostovaya, I.V. \& Skorik A.P. (1995). The Archetypes and the benchmarks of the Russian mentality // Political studies. No. 4. pp. 69-76.

Ovchinnikov, A.I., Mamichev A., Manastirniy A. V. \& Tyurin, M.E. (2009). Legal archetypes in the legal policy of Russia. Rostov on Don. pp. 287.

Political culture and political processes. SPb., 2007. pp.518.

Berger, P.L. \& Luckmann, T. (1966). The Social Construction of Reality. A Treatise on sociology of Knowledge. pp. 240.

Kononova O. \& Yakimova Z. (2013). Competence as an object for Assessmen and Measuremen in Training Quality Control System//World Applied Sciences journale. T. 27. pp. 536-540.

Kirsanova, L. \& Korotina O. (2014). On the Contents of the Protest Conscience in Russia. Wolrd Applied Sciences Journal 31(5): pp. 930-934.

Merton, R.K. (1957). Social Theory and Social Structure / Robert K. Merton. Enl. Ed. New York: Free press. pp. 198.

Muouffe, Ch. (2000). The Democratic Paradox. London: Verso. p. 36-59.

Rouland, N. (1988). Anthropologie Juridigue. Paris: Presses universitaires de France pp.300. 
ISSN 2039-2117 (online) ISSN 2039-9340 (print)
Mediterranean Journal of Social Sciences MCSER Publishing, Rome-Italy
Vol 6 No 3 S4 May 2015 